of the palms develops with conjunctival hyperemia and cracking of the lips. Perivascular hyperechogenicity in the coronary arteries snd mild mitral regurgitation was registered on the echo.

K.A.B., a 4-year-old girl, her disease started with fever and enlarged cervial lymph nodes on the right measuring $5 \times 3 \mathrm{~cm}$, so she was hospitalized and ceftriaxone therapy was introduced. Diagnosis of KD was made after the development of polymorphic rash, conjunctival hyperemia, edema and erythema of the palms and soles, and dry, cracking lips. Echocardiography revealed mild mitral regurgitation and uniformly broad LCA with hyperechogenicity.

I.Š., a 7-year-old girl had fever and right-sided cervical lymphadenopathy four days before admission and was treated as an outpatient with peroral cephalosporin. During hospitalization antibicrobial therapy was changed initially to ceftriaxone and azithromycin, then due to the absence of clinical and laboratory response to cefazolin and clindamycin. On the tenth day of the disease swelling of the hands and feet with conjunctival hyperemia and raspberry tongue were noted. Echocardiographically ectatic proximal part of LCA $(3.9 \mathrm{~mm})$ was registered and IVIG with ASA introduced. During the longterm follow-up no residual changes in the coronary arteries were recorded.

Conclusion The aim of this paper is showing that in an acute febrile disease one must also think about Kawasaki disease, especially when there is absence of adequate response to antibiotic therapy. Immunoglobulin therapy has been shown to prevent the development of serious cardiovascular complications and remains the first choice in the treatment of children with KD. In case of persistent fever and resistant cases, corticosteroids and other immunomodulatory and biological therapy may be considered.

\section{CAROTID INTIMA-MEDIA THICKNESS IN CHILDREN WITH INFLAMMATORY BOWEL DISEASE}

Tokić Pivac Višnja*, Herceg-Čavrak Vesna, Zrinjka Mišak, Iva Hojsak, Oleg Jadrešin, Sanja Kolaček. Children's Hospital Zagreb, Zagreb

10.1136/archdischild-2021-europaediatrics. 188

Carotid intima-media thickness (cIMT) reflects early structural changes on arteries and independently predicts cardiovascular risk in asymptomatic individuals. Previous studies showed increased cIMT in adult inflammatory bowel disease (IBD) patients compared with healthy subjects.

This study aims to identify early structural changes in carotid arteries in IBD patients as early as childhood and adolescence.

Methods The study includes 161 children with the mean age of $14.08 \pm 2.88$ (6-18) years - 55 with newly discovered active disease; 53 in clinical remission defined with disease activity pediatric indices for Crohn disease and ulcerative colitis (PCDAI, PUCAI); and 53 healthy subjects. We used an automatised edge-tracking system (Vivid E9, General Electrics, software 112 (1.7); linear probe 11L-D). In the longitudinal view, we measured cIMT on the posterior common carotid artery wall at end-diastole, $1 \mathrm{~cm}$ proximal to the bifurcation in a length of $1 \mathrm{~cm}$. We calculated the mean value of three measurements on each side. We used the ANOVA test (SPSS 20.0) for comparisons, with the level of significance $\mathrm{P}<0.05$.
Results mean cIMT value in patients with the active IBD was $0.49 \pm 0.05 \mathrm{~mm}$. Although we observed a slight increment in cIMT depending on the disease activity, the difference did not reach statistical significance $(\mathrm{P}=0.373)$. In patients with Crohn disease, cIMT was $0.48 \pm 0.04 \mathrm{~mm}$, and in children with ulcerative colitis, it was $0.49 \pm 0.05 \mathrm{~mm}(\mathrm{P}=0.336)$.

Conclusion An increase in cIMT reflects structural changes in arterial walls, which require time. It seems that such changes induced with chronic inflammation are not visible in the pediatric population, which emphasises a potential preventive role of a prompt, adequate anti-inflammatory treatment.

\section{ARTERIAL STIFFNESS IN CHILDREN AND ADOLESCENTS WITH INFLAMMATORY BOWEL DISEASE}

Tokić Pivac Višnja*, Herceg-Čavrak Vesna, Mišak Zrinjka, Hojsak Iva, Jadrešin Oleg, Kolaček Sanja. Children's Hospital Zagreb, Zagreb

\subsection{6/archdischild-2021-europaediatrics. 189}

Introduction Arterial stiffness increases with age. Various factors, including chronic inflammation, enhance this process. Adult patients with inflammatory bowel disease (IBD) have increased arterial stiffness despite the lower influence of other risk factors. It is not clear at which age these changes start.

This study aims to determine if there are visible changes in arteries of IBD patients as early as childhood and adolescence. Methods To identify subclinical changes in the arterial walls, we measured aortic pulse wave velocity (PWVao) using Arteriograph (Tensiomed) oscillometric device. We included in the study 70 children ( 7 to 18 years - mean age $14.39 \pm 2.93$ years), divided into three groups - patients with active IBD $(\mathrm{N}=15)$, in clinical remission $(\mathrm{N}=35)$, and healthy subjects $(\mathrm{N}=20)$. We used the Student's t-test for comparisons.

Results We did not observe a significant difference comparing PWVao in children and adolescents with IBD (PWVao=6.15 $\pm 0.90 \mathrm{~m} / \mathrm{s})$ and healthy subjects $(\mathrm{P}=0.83)$. We came to a similar observation comparing patients with the active disease with dose in clinical remission $(\mathrm{PWVao}=6.09 \pm 0.74 \mathrm{~m} / \mathrm{s}, 6.21 \pm 0.80$ $\mathrm{m} / \mathrm{s}$, respectively) $(\mathrm{P}=0.50)$. Likewise, there was no significant difference between PWVao of patients with active disease and healthy subjects. Arterial stiffness did not differ in patients with Crohn disease $(\mathrm{N}=30$; $\mathrm{PWVao}=6.18 \pm 0.66 \mathrm{~m} / \mathrm{s})$, ulcerative colitis $(\mathrm{N}=18 ; \mathrm{PWVao}=5.94 \pm 1.11 \mathrm{~m} / \mathrm{s})$ and controls $(\mathrm{P}=0.44)$. Two children had inflammatory bowel disease unclassified.

Conclusions arterial stiffness in children and adolescents with inflammatory bowel disease remains unchanged, which opens a possibility to prevent accelerated arterial vessel ageing apparent in adult IBD patients.

\section{LEFT VENTRICLE CARDIAC FIBROMA IN PATIENT WITH GORLIN - GOLTZ SYNDROME}

${ }^{1}$ Stjepan Herceg* ${ }^{*}$ 1,2Daniel Dilber, 1,2Dalibor Šarić, 1,2Dorotea Bartoniček, 1,2Marina Mihalec. 'School of Medicine, University of Zagreb; ' 2 Department of Cardiology, Clinic of Pediatrics, University Hospital Center Zagreb

\subsection{6/archdischild-2021-europaediatrics. 190}

Introduction Gorlin - Goltz syndrome (basal cell nevus syndrome - NBCSS) is an autosomal dominant disorder that is clinically presented by basal cell carcinomas, odontogenic keratocysts, perforated cavities on the palms and soles, skeletal 
anomalies, and a typical number of other phenotypes, including occurrence of cardiac fibroma. The syndrome is caused by microdeletion of the long arm of chromosome 9, in the region q22.3-q31 which includes the $\mathrm{PTCH}$ tumor suppressor gene. The diagnosis is made clinically, through large and small criteria that include the already mentioned clinical characteristics.

Case Report We will present the case of a 5 - year - old girl diagnosed with Gorlin - Goltz syndrome with the presence of fibroma in the left ventricular wall. The patient has an uneven psychomotor development and shows atypicalities in the field of socio-emotional functioning. Phenotypically, we find increased neurocranium, rough facial features, divergent strabismus, and a wider nasal root. The girl was initially hospitalized for the clinical presentation of heart failure: she was clinically tachydyspnoic, with audible crepitations in the lungs, enlarged liver, and pretibial edema. Echocardiographically, it was diagnosed with dilated cardiomyopathy, with an ejection fraction of $25 \%$, while the formation of an unclear etiology was seen in the left ventricle. The patient was treated with anticongestive therapy with low molecular weight heparin and further treatment was performed. MRI of the heart showed a formation that according to radiological criteria corresponds to a large fibroma. Due to the opinion that dilated cardiomyopathy and fibroma with phenotypic characteristics could be parts of systemic disease, molecular karyotyping was performed which found microdeletion of the long arm of chromosome 9 in the q22.3 region, which includes the PTCH gene that regulates cell growth and functions as a tumor suppressor gene. Haploinsufficiency of this gene has been described as Gorlin - Goltz syndrome, which is characterized by phenotypic traits such as those found in our patient. Among patients with Gorlin-Goltz syndrome, 10\% develop cardiac fibroma with the most common localization in the left ventricular cavity. Symptoms of cardiac fibroma depend on the size of the tumor, the involvement of the conduction system, and the possible existence of intracavitary obstruction. The patient we present has an extensive tumor located intramurally in the anterolateral wall of the left ventricle, measuring $5.8 \times 4.8 \mathrm{~cm}$. Measured values of cardiac pressures obtained by invasive cardiac treatment indicate impaired systolic and diastolic heart function and increased pulmonary pressure, as a result of dilated cardiomyopathy with clinical signs of heart failure.

Discussion The presence of dilated cardiomyopathy with markedly impaired systolic function may be secondary to the tumor or as primary disease, that is why genetic processing of cardiomyopathy is ongoing. Cardiac fibroma can be treated by surgical resection, but in a situation of severely impaired systolic function, transplantation treatment is more likely, with the risk of immuosuppression in a patient with a tumor suppressor gene disorder.

\section{FIRST CROATIAN GUIDELINES FOR DIAGNOSIS AND TREATMENT OF ARTERIAL HYPERTENSION IN CHILDREN AND ADOLESCENTS}

Vesna Herceg-Čavrak*, Dalibor Šarić, Hrvoje Kniewald, Višnja Tokić Pivac, Martin Ćuk, Ivana Trutin, Đurð̌ica Košuljandić, Adela Arapović, Dejan Balažin, Vera Musil, Vesna Jureša, Bojan Jelaković, Nikolina Benco, Bernardica Valent Morić. Klinika za dječje bolesti Zagreb

10.1136/archdischild-2021-europaediatrics.191
Hypertension in children and adolescents is a growing public health problem. The risk of developing hypertension in children is higher than ever before due to adverse circumstances such as obesity, excessive salt and processed food intake, reduced physical activity and stress. Hypertension is transmitted from childhood, and especially adolescence, into adulthood and thus increases the risk for cardiovascular disease in adulthood. As information regarding pediatric hypertension has changed over the last few decades, we have developed the first Croatian guidelines for the diagnosis and treatment of hypertension in children and adolescents based on recent literature and guidelines of international societies adapted to our circumstances. Fourteen doctors from different centers - members of the pediatric hypertension working group from the Croatian Society of Hypertension - participated in the development of our guidelines. We tried to cover various aspects of pediatric hypertension - epidemiology, prevention, primary and secondary hypertension, diagnosis, vascular phenotype factors, athlete hypertension, neonatal hypertension, treatment of hypertension and hypertensive urgency and emergency. With these recommendations, we tried to make it easier for doctors to cope with the issue of pediatric hypertension, as well as offer practical instructions on how to deal with such patients. These are all reasons why we believe that the guidelines, written by members of the Croatian Society of Pediatric Cardiology and Rheumatology, the Croatian Society of Pediatric Nephrology, the Croatian Society of School and University Medicine and the Croatian Society of Hypertension, will be useful in prevention, active search for hypertension in children and its treatment. The guidelines can be found on the website of the Croatian Society for Hypertension https://hdh.emed.hr/ upload/hdh_smjernica/dokument_1581600283.pdf

\section{ALAGILLE SYNDROME IN INFANT WITH FALLOT TETRALOGY}

${ }^{1}$ Stjepan Herceg*, 1,2Daniel Dilber, 1,2Dalibor Šarić, 1,2Dorotea Bartoniček, 1,2 Marina Mihalec, ${ }^{1,3}$ Sanda Huljev Frković, ${ }^{1,4}$ Dražen Belina, ${ }^{4}$ Željko Đurić, ${ }^{4}$ Mislav Planinc. ${ }^{1}$ School of Medicine, University of Zagreb; ${ }^{2}$ Department of Cardiology, Clinic of Pediatrics, University Hospital Center Zagreb; ${ }^{3}$ Department of Medical Genetics and Metabolic Diseases, Department of Pediatrics, University Hospital Center Zagreb; ${ }^{4}$ Department of Pediatric Cardiac Surgery, University Hospital Center Zagreb

\subsection{6/archdischild-2021-europaediatrics. 192}

Introduction Alagille syndrome is an autosomal dominant disorder that primarily affects the liver and heart. The genetic basis for the development of the syndrome is a mutation in the JAG1 gene (in most cases) or the NOTCH2 receptor. The syndrome is clinically characterized by chronic cholestasis, congenital heart defect (most often pulmonary stenosis), abnormalities in the skeletal system ('butterfly' vertebrae), changes on the eyes (posterior embryotoxon) and characteristic phenotype. The prevalence of the syndrome is estimated at 1:30 000 live births.

Case Report We will present a male infant aged 10 months with a diagnosis of Alagille syndrome. The boy was born from his mother's first, regularly controlled pregnancy. The boy was vital at birth with mild neonatal jaundice. On the third day of life, a systolic murmur was observed over the precordium, louder along the left edge of the sternum, and a diagnosis of tetralogy of Fallot was made by echocardiography. During the next examination, at the age of one month, the classic form of tetralogy of Fallot was verified by ultrasound 